\title{
VEDAÇÃO AO RETROCESSO E SEGURIDADE SOCIAL: A PROTEÇÃO DA SEGURANÇA E DA CONFIANÇA, A RESERVA DO POSSÍVEL E A NÃO REGRESSIVIDADE EM MATÉRIA DE DIREITOS FUNDAMENTAIS SOCIAIS
}

\section{PRINCIPLE OF NON-REGRESSION AND SOCIAL SECURITY: SECURITY AND TRUST PROTECTION, RESERVATION OF THE POSSIBLE AND NON- REGRESSION IN THE FUNDAMENTAL SOCIAL RIGHTS}

Rodrigo Garcia Schwarz ${ }^{1}$ Candy Florencio Thomé ${ }^{2}$

\section{RESUMO}

O presente artigo tem por escopo investigar, a partir da perspectiva das dimensões materiais e eficaciais dos direitos fundamentais sociais, as questões que concernem à relevância da segurança e da confiança para o pacto social instituinte e, em consequência, à não regressividade em matéria de direitos fundamentais sociais em geral e de seguridade social em particular. Promovendo o aprofundamento investigativo, através de pesquisa descritivoexplicativa do tipo documental-bibliográfica, dedica-se a problemas analítico-conceituais das teorias dos direitos fundamentais. Revela que, embora a vedação do retrocesso não seja absoluta, o retrocesso deve ser plenamente justificado.

Palavras-chave: Confiança, Não regressividade, Reserva do possível, Seguridade social, Solidariedade

\begin{abstract}
This paper aims to explain and analyze, from the perspective of the material and effective dimensions of fundamental social rights, questions that concern the relevance of security and trust for the social pact and, as a consequence, to the non-regression in the fundamental social rights in general and in the social security in particular. It reveals that, while the retrogression is not absolute, retrogression must be fully justified. The research is descriptive and explanatory, documentary-bibliographical.
\end{abstract}

Keywords: Trust, Non-regression, Reservation of the possible, Social security, Solidarity

\footnotetext{
${ }^{1}$ Doutor em Direito e em História Social pela, Pontifícia Universidade Católica de São Paulo, PUC/SP, (Brasil). Professor da Universidade do Oeste de Santa Catarina. PPGD, (Brasil). E-mail: rgschwarz@gmail.com.

${ }^{2}$ Doutora em Direito, Universidade de São Paulo e Universidad de Castilla-La Mancha, (Espanha). Professora da Fundação Getúlio Vargas - PPPGD - São Paulo, (Brasil). E-mail: candyflor@gmail.com.
} 


\section{INTRODUÇÃO}

O presente artigo tem por escopo investigar, a partir da perspectiva das dimensões materiais e eficaciais dos direitos fundamentais sociais e do direito à seguridade social em particular, as questões que concernem à relevância da segurança e da confiança para o pacto social instituinte e, em consequência, à não regressividade em matéria de direitos fundamentais sociais em geral e de seguridade social em particular. Promovendo o aprofundamento investigativo, através de pesquisa descritivo-explicativa do tipo documental-bibliográfica, dedica-se a problemas analítico-conceituais das teorias dos direitos fundamentais, sobretudo às questões da proteção da segurança e da confiança, da reserva do possível e do princípio de não regressividade, com principal foco na doutrina e na jurisprudência. Revela que, embora a vedação do retrocesso não seja absoluta, este - o retrocesso - deve ser plenamente justificado, de forma que aquelas medidas que implicam retrocesso em matéria de direitos fundamentais sociais, especialmente no âmbito dos direitos da seguridade social, devem ser consideradas medidas logicamente violadoras dos deveres do Estado e, portanto, devem estar sujeitas a um alto grau de sindicabilidade constitucional - só se justificando se, de fato, comprovadamente, estiverem destinadas à efetiva viabilização da própria seguridade social, tendo-se, sobretudo, em conta, as bases de viabilização possíveis a partir da necessária conciliação possível entre princípios como o da universalidade da cobertura e do atendimento, no que diz respeito à extensão dos benefícios sociais, e o da diversidade da base de financiamento, no que diz respeito ao custeio desses mesmos benefícios, com fulcro no princípio estrutural de solidariedade.

\section{A FUNDAMENTALIDADE ESTRUTURAL DA SEGURIDADE SOCIAL, DIRETO SOCIAL FUNDAMENTAL}

É sabido que os direitos econômicos, sociais e culturais, ou simplesmente direitos sociais $^{3}$, dizem respeito a questões relacionadas a expectativas básicas para a vida e a dignidade

\footnotetext{
${ }^{3}$ Segundo Carías (1979) e Esping-Andersen (1998), os direitos sociais estão associados aos sistemas de proteção social que se constituem e consolidam, com maior ou menor ênfase, na Europa Ocidental e em muitos países da América entre o terço final do século XIX e o segundo pós-guerra, no contexto do chamado "Estado social de direito", um projeto político concreto, sucessor do Estado liberal de direito, e/ou do chamado "Estado de bemestar social" (welfare state), um peculiar plexo de políticas públicas sociais que empreende o Estado capitalista
} 
humanas, entre elas o direito ao trabalho e à seguridade social, a proteção à maternidade, a proteção à infância e a assistência aos desamparados, relacionando-se ao "mínimo social" (RAWLS, 1980) - ou, em outros termos, ao “mínimo existencial” (BOROWSKI, 2003) -, ou seja, ao próprio conteúdo essencial - o conteúdo (nuclear) mínimo - dos direitos reconhecidos como fundamentais nas constituições contemporâneas, atuando como verdadeiras premissas materiais para o exercício de outros direitos fundamentais segundo essas mesmas constituições, como os direitos civis e políticos ${ }^{4}$.

Assim, os direitos fundamentais sociais - entre eles, o direito à seguridade social - são verdadeiramente imprescindíveis, concomitantes meio e condição para a promoção do desenvolvimento humano, da liberdade e da autonomia da pessoa, da erradicação da pobreza e da marginalização, da redução das desigualdades e de outros objetivos do Estado democrático de direito.

Os direitos relacionados à seguridade social integram, segundo a Declaração Universal dos Direitos Humanos, o catálogo dos direitos humanos ${ }^{5}$. Além disso, os direitos relacionados à seguridade social são reconhecidos como direitos fundamentais no âmbito do PIDESC (Pacto Internacional de Direitos Econômicos, Sociais e Culturais), do "Protocolo de San Salvador" (Protocolo Adicional à Convenção Americana sobre Direitos Humanos em Matéria de Direitos Econômicos, Sociais e Culturais), da Declaração Sociolaboral do Mercosul e do Convênio Ibero-americano de Seguridade Social.

Essas grandes declarações de direitos destacam-se, em relação aos direitos fundamentais sociais - entre eles, o direito à seguridade social -, pela consideração, em comum, nos seus

\footnotetext{
em determinadas conjunturas, sobretudo a partir da grande crise econômica de 1929 (a "Grande Depressão"), com o objetivo de alavancar a eficiência dos mercados e organizar mais eficientemente a produção (ANDERSSON, 2005). Um traço comum da regulação jurídica desses âmbitos, produto de incontáveis lutas e reivindicações sociais e da racionalização da intervenção estatal na economia, seria a utilização do poder estatal com o propósito precípuo de corrigir situações de desigualdade material (MIRAVET, 2003), "sea a partir del intento de garantizar estándares de vida mínimos, mejores oportunidades a grupos sociales postergados, compensar las diferencias de poder en las relaciones entre particulares o excluir un bien del libre juego del mercado", de forma que os direitos sociais são "fruto del intento de traducir en expectativas (individuales o colectivas) respaldadas legalmente el acceso a ciertos bienes configurados en consonancia con la lógica de este modelo" (ABRAMOVICH, COURTIS, 2006, p. 17).

${ }^{4} \mathrm{Na}$ Conferência Internacional de Direitos Humanos de 1993, em Viena, foi definitivamente legitimada a ideia da indivisibilidade dos direitos humanos, sejam eles civis e políticos ou econômicos, sociais e culturais, como fundamental para o desenvolvimento humano.

${ }_{5}^{5}$ Para uma distinção básica entre as ideias de direitos humanos e de direitos fundamentais, v. Ferrajoli et al. (2001, pp. 76 et seq.), Marshall e Bottomore (1998) e Martínez (1995).
} 
preâmbulos, da estreita relação que existe entre a vigência (eficácia) dos direitos fundamentais sociais e a vigência (eficácia) dos direitos civis e políticos, reconhecendo que as diferentes categorias de direitos - civis, políticos, sociais - constituem um todo indissolúvel que encontra a sua base axiológica e filosófico-normativa na dignidade humana, razão pela qual esses direitos exigem - todos - tutela e promoção permanentes e concomitantes, com o objetivo de alcançarse sua vigência (eficácia) plena, sem que jamais se possa justificar a violação de uns a pretexto da realização de outros ${ }^{6}$.

Dessa forma, pode-se afirmar que todos esses direitos humanos fundamentais têm como fundamento a dignidade humana e são indivisíveis e interdependentes. A realização dos direitos fundamentais sociais, como aqueles relacionados à seguridade social, é imprescindível à existência real - substantiva - de direitos civis e políticos, cuja concretização e exercício requerem a superação de necessidades humanas básicas. Por outro lado, os direitos civis e políticos são indispensáveis como mecanismos de reivindicação e controle social do cumprimento das obrigações que emanam dos direitos fundamentais sociais. Assim, o desenvolvimento de um direito facilita o desenvolvimento de outros direitos; da mesma forma, a carência de um direito também afeta os outros direitos, debilitando-os (THOMÉ, 2012).

Por isso, embora a discussão a respeito dos direitos fundamentais sociais, da sua imprescindibilidade e das suas garantias - sobretudo no que concerne ao âmbito da seguridade social - habitualmente esteja associada às necessidades das pessoas em situação de maior vulnerabilidade no âmbito social (PISARELLO, 2007), para as quais o acesso aos recursos necessários para a satisfação de necessidades vitais básicas tende a ser meramente residual e insuficiente, essa discussão interessa, na realidade, a todas as pessoas, pois, envolvendo os princípios reitores das ordens econômica e social em diversos âmbitos geopolíticos, as expectativas que concernem aos direitos fundamentais sociais, em especial aquelas relacionadas à seguridade social, implicadas em disputas alocativas, põem em relevo a igualdade material (SANCHÍS apud CARBONELL, PARCERO E VÁZQUEZ, 2001) e dizem respeito ao

\footnotetext{
${ }^{6}$ Nesse sentido, v. os preâmbulos da Declaração Universal dos Direitos Humanos, do Pacto Internacional de Direitos Econômicos, Sociais e Culturais e do "Protocolo de San Salvador". A par das concepções de vigência e de eficácia, como propriedades relacionadas, mas diferenciadas, da norma jurídica, há que ressaltar que as normas internacionais, ao proclamarem a necessidade de vigência plena dos direitos humanos fundamentais, estão, também, proclamando a necessidade de sua eficácia.
} 
chamado "mínimo social" ou "mínimo existencial" - econômica, social e culturalmente delineado -, conjunto de bens necessários não só para a sobrevivência em condições condizentes com a dignidade inerente à pessoa, mas também para garantir a ela as condições materiais que viabilizam o exercício real de outros direitos fundamentais, imprescindíveis à democracia e à cidadania integral ${ }^{8}$.

Assim, o progressivo reconhecimento das expectativas relacionadas aos direitos fundamentais sociais no plano constitucional e em tratados internacionais - e a sua consequente integração à ordem jurídica interna de cada país -, embora não possa ser associado a um processo linear, cronológico e unívoco - porque, segundo Baldasarre (2001) e Polanyi (1998), não existe um padrão único no reconhecimento dos direitos fundamentais sociais pelos diferentes países, concomitantemente reivindicados e atribuídos, conquistados e concedidos, impõe obrigações, positivas e negativas, aos poderes públicos - e também, em maior ou menor grau, aos particulares ${ }^{9}-$, concernentes à satisfação de tais necessidades e, em consequência, à efetiva promoção do desenvolvimento humano.

Daí a fundamentalidade dos direitos sociais e, em especial, dos direitos relacionados à seguridade social, fundamentalidade que impõe o respeito, pelos poderes públicos e pelos particulares, às expectativas geradas no seu âmbito, imprescindíveis à segurança social, fundamentalidade que deve, também, ser compreendida à luz do princípio estrutural de solidariedade, um avançado desdobramento da ideia de fraternidade que se projeta, sobretudo, sobre a seguridade social como base do pacto social instituinte.

\footnotetext{
${ }^{7}$ Segundo Barcellos (2002, p. 198), o "mínimo existencial" corresponde ao conjunto mínimo de bens materiais imprescindíveis para a existência humana em condições decentes: o mínimo existencial corresponde, portanto, ao próprio núcleo material da dignidade humana, ou ao conteúdo essencial dos direitos fundamentais (BOROWSKI, 2003, p. 66): verdadeiro meio e concomitante condição necessária para que a pessoa possa gozar plenamente dos seus direitos civis e políticos e participar da vida política de uma comunidade.

${ }^{8}$ Nesse sentido, Marshall (1992) estabelece uma relação de dependência entre a cidadania e a soma dos direitos civis, políticos e sociais do cidadão: os direitos civis diriam respeito aos direitos "necessários à liberdade individual"; os direitos políticos, aos direitos "de participação no exercício do poder político"; e os direitos sociais a "todo um conjunto de direitos, desde o direito a um mínimo de bem-estar e segurança econômica até ao direito a partilhar em pleno na herança social e a viver a vida de um ser civilizado de acordo com os padrões prevalecentes na sociedade". Segundo Kliksberg (1997), o acesso à efetiva cidadania é um direito fundamental, o primeiro dos direitos, porque sem ele não se tem acesso aos outros direitos, mas aquele - $\mathrm{o}$ acesso à cidadania -, naturalmente, compreende o gozo dos direitos sociais, ao menos na sua expressão mínima: o "mínimo existencial".

${ }^{9}$ Sobre a eficácia dos direitos fundamentais frente a terceiros, v. Luño (1999) e Reis (2005). No Brasil, o Supremo Tribunal Federal, no julgamento dos Recursos Extraordinários 158.215-4/RS, 161.243-6/DF e 20819/RJ, já decidiu que os direitos fundamentais vinculam diretamente não apenas os poderes públicos, estando direcionados também à proteção dos particulares em face dos poderes privados.
} 


\section{A SEGURIDADE SOCIAL E O PRINCÍPIO ESTRUTURAL DE SOLIDARIEDADE, BASE DO PACTO SOCIAL INSTITUINTE}

Em relação à seguridade social, é sabido que o homem, por natureza, não é dotado de autossuficiência. Assim, mesmo no auge da sua capacidade produtiva, não foge à dependência em relação a outros homens, pois nem lhe é viável produzir, pelo trabalho, tudo o que tem capacidade ou mesmo necessidade de consumir, nem consumir tudo o que tem capacidade de produzir (SIMÕES, 1967).

Essa realidade, que se mantém imutável no curso da sua existência, é fruto da própria natureza social do homem, mas se avulta substancialmente diante de adversidades ou contingências - eventos como doenças ou o avançar da idade - que lhe reduzem, ou mesmo retiram, a capacidade produtiva e, em consequência, a capacidade de prover a sua própria subsistência. Nesse contexto, a seguridade social é a resposta a um anseio por segurança, sobretudo quanto ao futuro, inerente ao homem enquanto ser dotado de capacidade produtiva, que se reflete sobre todo o grupo social, substituindo o sentimento fraterno por uma solidariedade de cunho mais amplo, induzida ou mesmo imposta por lei.

O sistema de seguridade social é, portanto, no âmbito dos direitos fundamentais sociais, um instrumento de solidariedade desde as suas origens, mas que apenas em suas origens mais remotas comporta certa afinidade com a ideia de fraternidade. Na América pré-colombiana, no Império Inca, encontramos, por exemplo, uma das primeiras manifestações de um sistema de seguridade social, entendido como um sistema racional de conjugação de esforços organizados da sociedade para prover uma espécie de seguro social: o regime de propriedade então existente previa o cultivo, através do trabalho comum, de determinadas terras, cujo produto tinha a finalidade de atender às necessidades alimentares dos anciãos, dos doentes ou inválidos e dos órfãos, desprovidos de capacidade produtiva (OLIVEIRA, 1989).

A seguridade social, todavia, como a conhecemos, é fruto de conquistas históricas e recentes dos trabalhadores, consubstanciadas em marcantes produções legislativas. Nasce, na sua concepção contemporânea, ao final do século XIX, na Alemanha de Bismarck, em meio às tumultuadas greves e à pesada repressão policial que marcam o último quartel daquele século na Europa continental. No Brasil, o sistema só se efetivou a partir dos conflitos trabalhistas que marcaram o início do século XX (greves de 1917/19), estendendo-se inicialmente apenas a 
algumas categorias profissionais, detentoras de maior poder de reivindicação. A elaboração dos modernos sistemas de seguridade social está, portanto, desde a sua gênese, quer na Europa, quer, de forma tardia, no Brasil, vinculada à capacidade de reivindicação organizada de determinados segmentos do operariado, fato que corrobora a ideia de que os direitos fundamentais sociais, sobretudo aqueles relacionados à regulação do trabalho e à seguridade social, são, na realidade, um direito conquistado pelos trabalhadores (em especial por determinados grupos com maior capacidade de organização à época) no âmbito do conflito subjacente à luta de classes, mas, também, de alguma forma, uma concessão.

O surgimento dos modernos sistemas de seguridade social está estruturalmente associado aos problemas decorrentes do advento do capitalismo industrial, que redundou em profundas transformações no modo de vida e na estrutura produtiva, contexto em que se verifica uma cisão completa entre a titularidade do trabalho e a dos meios de produção, com a imposição, pelo Estado, de uma solidariedade estrutural que servisse, inclusive, de freio aos crescentes conflitos entre o capital e o trabalho - não por acaso, as leis sociais de Bismarck foram levadas a cabo após a repressão franco-germânica à Comuna de Paris; da mesma forma, através da criação da Organização Internacional do Trabalho, em 1917, o capitalismo europeu tratou de dar uma resposta à Revolução Soviética; e, por fim, a constitucionalização dos direitos sociais em Weimar, em 1919, claramente, teve por fulcro a necessidade de pacificação social após os eventos desencadeados a partir da Revolução de Kiel, em 1918.

No Brasil, o princípio da solidariedade concretiza-se nos direitos fundamentais sociais em especial, mas não se esgota neles, irradiando-se sobre a Constituição como um todo ${ }^{10}$. O Estado democrático de direito consiste, nesse contexto, na persecução de justiça social, segurança social e assistência social, desvelando-se a solidariedade, a partir disso, mais do que simples expressão de um dever fraterno, moral, como direito e dever dos membros de um determinado grupo social (solidariedade de grupos sociais homogêneos) ou de toda a sociedade (solidariedade genérica), base do pacto social instituinte.

\footnotetext{
${ }^{10}$ Nesse contexto, a solidariedade pode ser entendida, “(...) quer em sentido objetivo, em que se alude à relação de pertença e, por conseguinte, de partilha e de co-responsabilidade que liga cada um dos indivíduos à sorte e vicissitudes dos demais membros da comunidade, quer em sentido subjetivo e de ética social, em que a solidariedade exprime o sentimento, a consciência dessa mesma pertença à comunidade" (YAMASHITA, 2005, p. 56).
} 


\section{A EXPECTATIVA E A CONFIANÇA: A RELEVÂNCIA DA SEGURANÇA E DA CONFIANÇA PARA O PACTO SOCIAL INSTITUINTE}

Há, na atualidade, nos países ocidentais, uma concepção bastante consolidada do Estado de direito como um ideal jurídico-político articulado e coerente de instituições e valores diversos que se sedimentaram na cultura constitucional democrática - e, com ela, nos ordenamentos jurídicos - ao longo de mais de dois séculos. O Estado de direito, como produto dessa evolução histórica a partir de suas origens no iluminismo, não seria já, como verificamos anteriormente, apenas um Estado formalmente submetido a normas jurídicas, mas um Estado que haveria incorporado - e no qual se desenvolveriam com cada vez maior ênfase - exigências cada vez mais definidas sobre os direitos civis e políticos, o processo democrático e a igualdade econômico-social dos cidadãos/administrados (os direitos fundamentais sociais).

Nesse contexto, tendemos a conceber o Estado de direito como um universo dentro do qual se contém quase todos aqueles princípios éticos e políticos que constituem os cânones da legitimidade dos ordenamentos jurídicos: uma sociedade bem ordenada, com um direito justo, seria aquela que se articula institucionalmente de acordo com essas exigências do Estado (democrático) de direito. Portanto, Estado democrático de direito, sociedade justa e legitimidade política vêm a ser, todos, conceitos com um alcance axiológico equivalente ${ }^{11}$.

Tratamos, agora, de um desses princípios peculiares, o primeiro e principal a partir de um ponto de vista lógico - aquele que se denomina ou categoriza, sobretudo a partir de uma tradição anglo-saxã, como "império da lei”"12. O Estado de direito é, antes de tudo, um Estado - uma sociedade política - no qual a lei como fonte de normas jurídicas tem uma posição dominante. $\mathrm{O}$ que em sua origem histórica pode haver sido, talvez, um ideal em favor da submissão do poder do rei ou da nobreza ao direito comum (common law) baseado no costume ou aos direitos pactuados nos parlamentos medievais, transformou-se através de um processo de racionalização (WEBER, 1964), em uma clara exigência de que a fonte primária do direito

\footnotetext{
${ }^{11}$ Nesse sentido, v. Böckenförde (1991), Díaz (1971) e Ferrajoli (1995).

${ }^{12}$ A tradução de Rule of Law como império da lei (ou governo da lei) é discutida por aqueles que pensam que o termo Law concerne ao direito em geral. A tradução mais precisa, de acordo com essa posição, seria "império do direito". Na realidade nas origens anglo-saxãs do conceito, a referência se fazia à common law de origem predominantemente jurisprudencial, mas, posteriormente, com o dogma da soberania do parlamento, se traslada às normas criadas por este. Na Europa continental, ao contrário, tradicionalmente o "império da lei” foi pensado em sentido estrito, e assim passou à semântica revolucionária francesa como regne de la loi e chegou à Alemanha como Herrschaft des Gesetzes.
} 
e de superior hierarquia seja a lei - as leis. É, portanto, às leis assim concebidas que se deve submeter o poder político e social segundo essa concepção de Estado de direito ${ }^{13}$.

Para possibilitar a identificação, o conhecimento e a proeminência dessa fonte superior do direito que é a lei é que surge no pensamento dos grandes teóricos do Estado de direito ${ }^{14} \mathrm{o}$ desenho institucional da separação de poderes, uma construção artificial destinada a definir com claridade e segurança o órgão legislativo - destacando a função legislativa das demais funções do Estado - que é a origem dessa lei, dessa norma hierarquicamente superior da ordem jurídica.

Com o funcionamento do aparato da "separação de poderes" - na verdade, separação de funções ou divisão de responsabilidades -, expressa-se plasticamente a subordinação de todos os poderes do Estado ao Poder Legislativo, ou seja, à lei (em última análise, à vontade popular consubstanciada no Poder Constituinte): o Poder Executivo deve se submeter ao princípio da legalidade e o Poder Judiciário deve motivar sempre nessa mesma legalidade as suas decisões. Nada há, pois, acima da lei; daí que, quando se fala, historicamente, em “império da lei”, se pretende cumprir a aspiração de alcançar um sistema político em que se vive sob um "governo de leis" e não sob um "governo de homens"15.

O documento histórico fundamental para contemplar em sua origem esse ingrediente primário do Estado de direito é a declaração francesa de 1789; nela, a Lei, la Loi (assim, grifada com maiúscula), à qual se apela explicitamente doze vezes em um breve texto de dezessete artigos, aparece como a norma decisiva. Os aspectos mais importantes da vida do cidadão/administrado na comunidade política são estabelecidos pela lei. Só a lei pode definir

\footnotetext{
${ }^{13}$ É claro que, sendo o Estado democrático de direito um Estado constitucional, o império da lei é, antes de tudo, o império da Constituição, lei maior, e das leis que se produzem de acordo com aquela.

${ }^{14}$ Por exemplo, Locke (1990), Montesquieu (1951) e Rousseau (1962).

${ }^{15}$ Atribui-se a primeira intuição dessa ideia a Platão (1872): se a lei verdadeira é aquela que visa ao bem comum, e se é essa lei que deve ter primazia em um regime digno deste nome, os homens mais aptos aos postos de comando na cidade serão aqueles que se revelarem como os mais obedientes e devotados àquilo que essas leis prescrevem. Esses homens, na verdade, deverão ser qualificados não de governantes, mas de servidores das leis, e isso, não por um gosto qualquer pelas inovações linguísticas, mas em virtude da compreensão de uma questão vital, da qual depende a ruína ou salvação da cidade: nas cidades onde a lei é subordinada e sem força, a perdição se mostra como certa; mas naquelas onde a lei é déspota e senhora das autoridades, e as autoridades, escravas da lei, temos aí a salvação e todos os bens que os deuses concedem às cidades. Mas a fórmula explícita moderna aparece pela primeira vez em 1656, na Oceana de Harrington (1992, p. 8): "Government (to define it de jure or according to ancient prudence) is an art whereby a civil society of men is instituted and preserved upon the foundation of common right or interest or (to follow Aristotle and Livy) it is the empire of laws and not of men". O Estado constitucional é, assim, e em primeiro lugar, o Estado com uma Constituição limitadora do poder através do império do direito - o "governo das leis e não dos homens" (BOBBIO, 1995, pp. 169 et seq.), o "Estado submetido ao direito" (CANOTILHO, 2002, p. 98).
} 
os limites comuns dos direitos individuais, o que está permitido e o que está proibido, o que é delito e o que é pena. À lei está reservada a tarefa de desenhar o círculo da liberdade em torno dos indivíduos; nenhuma obrigação e nenhuma carga pode fazer-se gravitar sobre eles sem a existência de uma lei prévia que as defina. Ao estabelecer-se assim, com caráter excludente, à lei a função de definir todos esses âmbitos de convivência, desenha-se outra das instituições constitucionais derivadas do império da lei: a reserva da lei.

Por que se atribui à lei essas tão altas e exclusivas competências? A resposta vem de modo imediato ao pensamento de Rousseau (1962) e está refletida na declaração de 1789: a lei é a expressão da vontade geral - "La Loi est l'expression de la volonté générale”. E a vontade geral é soberana. A partir da elaboração moderna da noção de soberania como poder superior de uma república, em 1576, por Bodin (1966) se relaciona a esse soberano como primeiro atributo o poder de dar leis a todos em geral e a cada um em particular. Assim, poder superior e lei se encontram no mesmo plano e aparecem como duas dimensões de uma mesma realidade: a dimensão política, que reflete o poder máximo, e a dimensão jurídica, que se expressa na fonte do direito de superior hierarquia. Naturalmente, quando se atribui esse poder soberano à vontade do demos, a lei passa a ser a expressão normativa dessa vontade soberana.

Com isso se desenham os perfis que deve possuir a lei para que se postule dela essa superioridade: (a) ser formalmente a "linguagem" através da qual fala o soberano e ser por isso mesmo o único instrumento normativo que pode interferir na liberdade e na propriedade dos cidadãos/administrados; e (b) ter uma posição formalmente superior e possuir a capacidade de estabelecer as condições para o exercício dos direitos básicos. Esses dois perfis permanecerão ao longo do século XIX como as duas almas, os dois espíritos da lei, e se fará referência a eles como lei em sentido formal e lei em sentido material. Ao lado desses perfis básicos se predica também das leis toda uma sorte de propriedades estruturais que formam parte de uma larga tradição conceitual ou têm uma conexão direta ou indireta com eles.

As leis, portanto, tendem a ser assim consideradas apenas se são gerais, ou seja, se têm como destinatários todos os cidadãos, sem distinções ou privilégios. Aqui se unem um pensamento tradicional - o rei ou imperador pode governar a todos, pois está acima dos senhores territoriais - e uma ideia nova - todos são iguais perante a lei, sem que se possam estabelecer regimes particulares ou privilégios frente a ela. 
Ou também, as leis devem ter certa estabilidade, dada a sua importância e solenidade, porque do contrário essas leis se contagiariam de debilidade e volatilidade do arbítrio caprichoso. Uma vez mais se unem aqui virtuosamente ideias antigas - as leis concernem à razão e à justiça, que são, por natureza, pautas que tendem à imobilidade - e ideias novas - os cidadãos devem ter garantias (previsibilidade) sobre o futuro da sua liberdade e dos seus direitos.

Como consequência de sua importância para o cidadão, as leis devem ser discutidas e aprovadas publicamente e devem ser promulgadas por escrito, em uma linguagem razoavelmente clara e precisa. Essa natureza de instrumento normativo público e escrito que se dirige à conformação das relações entre os cidadãos dá à lei um sabor racional, de projeção para o futuro, reflexivo, artificial e deliberado, diferentemente da regulação tradicional ancorada nos usos e costumes, que olha para o passado e quer imobilizar a memória jurídica para guardar a normatividade "sedimentada", inviolável e quase natural. A lei moderna é, ao contrário, um instrumento, uma alavanca de reforma e inclusive de educação cidadã, uma construção deliberada para possibilitar a emancipação humana, um fruto da racionalidade que interfere no imobilismo da tradição ${ }^{16}$.

Nesse sentido, não sem tensões e diferenças segundo os tempos e lugares, ela (a lei) luta para impor-se como fonte superior de direito frente aos veículos tradicionais de normas jurídicas, como o costume, o direito jurisprudencial ou as velhas recopilações pré-modernas que incluíam assistematicamente grande parte das normas de séculos atrás.

A época moderna que vê desenvolver-se a noção de Estado de direito é, pois, a época em que a vigência normativa por excelência aspira ser a vigência da lei. E como consequência do fato dessa vigência normativa das leis, afirma-se que se alcança - ou se realiza, ou se cumpre - certo objetivo, valor ou bem, tanto de natureza individual quanto de natureza pública, que se denomina tradicionalmente "segurança jurídica" ou "certeza do direito". O império da lei como ideal vincula-se, assim, à meta de assegurar a certeza do direito (o predicado da previsibilidade) e, com ela, a segurança jurídica dos cidadãos.

\footnotetext{
${ }^{16}$ A lei, portanto, não se submete à natureza, à realidade; a lei, fruto da vontade soberana do demos, impregnada dos valores eleitos por esta vontade, modifica, transforma a realidade. Por isso, a lei é, necessariamente, vertida em linguagem prescritiva - dever-ser: é orientada para incidir sobre a realidade, orientando, assim, a disciplina da convivência social.
} 
Nesse contexto, da certeza do direito e da segurança jurídica, em primeiro lugar, temos que recordar o que queremos sinalizar quando afirmamos que uma lei está vigente em determinada sociedade. De forma simples, podemos elencar algumas condições que necessariamente devem estar presentes para que se possa afirmar que uma regra existe em um grupo social (HART, 1961; BAYÓN, 1991):

a) existe - de fato - uma regularidade nos comportamentos dos membros dessa sociedade sempre que se dão determinadas circunstâncias ou condições;

b) quando se produz algum desvio a respeito desse comportamento regular, tende a darse, entre os destinatários dessas expectativas, certa reação crítica;

c) essas reações críticas frente aos desvios consideram-se justificadas;

d) os membros do grupo social recorrem a normas (regras) formuladas em termos linguísticos e normativos para justificar tanto a regularidade de comportamentos - as expectativas - quanto as críticas aos desvios.

Quando essas quatro condições se encontram presentes, podemos dizer que uma regra social existe ou está em vigor nesse grupo humano. Sobre a tela de fundo dessas condições, que são verdadeiros fatos sociais complexos, há de iniciar-se a reflexão sobre o que se denomina ou categoriza como "segurança jurídica". Ao fazê-lo, veremos, passo a passo, como vão aparecendo ingredientes, mecanismos e dimensões que vão perfilando cada vez mais delineadamente essa ideia e algumas outras conectadas a ela.

O momento imediato em que se suscita a possibilidade de podermos começar a falar em segurança jurídica produz-se pela mera existência dessas condições: sobretudo a da regularidade constante nas condutas da maioria dos membros do grupo. Como ocorre com qualquer regra social, o conhecimento da mesma (da regra) e a existência de fato de uma regularidade conforme a ela no comportamento dos membros de um grupo social (da conduta) trazem consigo a possibilidade de contar com um dado sobre o seu atuar futuro (expectativa). Poder ter em conta o que provavelmente vai acontecer a partir do conhecimento do que habitualmente acontece - ou seja, poder utilizar esse conhecimento como critério para prever uma conduta "esperada" e suas consequências - é algo que configura o núcleo do que são as condições de possibilidade da própria vida social. A expectativa mais ou menos certa sobre a conduta dos demais membros da coletividade introduz em nossas vidas um primeiro grau de segurança, sem o qual seria virtualmente impossível (con)viver harmoniosamente. 
Aqui aparece a dimensão fundamental da ideia de segurança que vamos desenhar: tratase, basicamente, de uma certeza, de uma sorte de conhecimento prévio do que (provavelmente) acontecerá em determinadas situações/condições. Muitas das atividades e circunstâncias que empreendemos na nossa vida social quotidiana têm essa certeza na sua base. Simplesmente lidamos facilmente - quase inconscientemente - com essas certezas em virtude do nosso conhecimento a respeito das regras sociais, implícitas ou explícitas, da nossa comunidade. A existência empírica de múltiplas regras na nossa sociedade nos poupa de indagações ou cálculos. Como a conduta dos seres humanos não está submetida a "leis naturais" suscetíveis de conhecimento público e prévio, temos que subordiná-la a normas ou regras generalizadas (generalizáveis) para que possamos prevê-la no nosso dia-a-dia. A existência da regra como mera regularidade de comportamento nos permite, assim, arriscar todos os dias contando com um prognóstico suficientemente exato a respeito do que vai acontecer no nosso entorno quotidiano (LAPORTA, 2002). Essa "segurança" fática é o primeiro grau de certeza que subministra, por si só, a mera existência de regras sociais e jurídicas ${ }^{17}$. A existência dessa ordem jurídica é o que gera essa certeza institucional que é a segurança jurídica.

Daí a importância das expectativas socialmente geradas a partir da própria norma jurídica e do princípio da confiança: espera-se, de todos, que sejam responsáveis e atuem de acordo com as normas estatuídas em sociedade.

\section{A RESERVA DO POSSÍVEL E O PRINCÍPIO DA NÃO REGRESSIVIDADE EM MATÉRIA DE DIREITOS FUNDAMENTAIS SOCIAIS}

Especialmente no âmbito das políticas de seguridade social, o tema da reserva do possível vem ganhando importância teórica e prática. A efetivação dos direitos fundamentais sociais, sobretudo do direito fundamental à seguridade social, tem exigido um profundo redimensionamento do papel da política e das instituições jurídicas no corpo social. Aquele modelo de cunho marcadamente conservador, no mais das vezes pouco sensível às demandas sociais e às lutas pelo direito a ter direitos, e infenso a mecanismos de tutela e controle judicial no que diz respeito ao delineamento das políticas - programas reunidos em torno da realização

\footnotetext{
${ }^{17}$ Nesse sentido, Díaz (1971, p. 44) afirma que "La legalidad engendra seguridad: el derecho establece y delimita el campo dentro del cual, en una determinada sociedad, los ciudadanos pueden sentirse seguros, sabiendo con certeza a qué atenerse en relación con sus derechos y deberes".
} 
de objetivos socialmente relevantes, politicamente determinados de acordo com o projeto consubstanciado na Constituição -, vem sendo superado por um novo modelo, mais democrático, socializante e inclusivo, em que o Estado assume obrigações prestacionais onerosas (que demandam recursos financeiros) e, ao buscar efetivá-las, mediando disputas alocativas (disputas pelos recursos financeiros), dialoga com os distintos anseios dos diferentes atores sociais, concertando-os em conformidade com o pacto social instituinte.

Nesse contexto de redimensionamento do papel social do Estado, o Comitê de Direitos Econômicos, Sociais e Culturais da Organização das Nações Unidas tem sustentado que os poderes públicos têm a obrigação de assegurar, em todo o momento, mesmo diante da reserva do possível, ao menos os conteúdos essenciais de cada um dos direitos sociais fundamentais, como o direito à seguridade social, impondo aos Estados um dever de não regressividade em matéria de direitos sociais ${ }^{18}$.

Esse mesmo princípio, de irreversibilidade das conquistas sociais, foi articulado constitucionalmente na Alemanha a partir da Lei Fundamental de Bonn (1949) ${ }^{19}$, como corolário da força normativa da Constituição e do conteúdo mínimo dos direitos fundamentais nela reconhecidos, e se irradiou para diversos ordenamentos, como o português ${ }^{20}$, o francês ${ }^{21}$, o espanhol $^{22}$, o colombiano ${ }^{23}$ e o brasileiro ${ }^{24}$.

Diferentes ordenamentos consagram a obrigação dos Estados, de respeito ao conteúdo mínimo ou essencial dos direitos sociais reconhecidos como fundamentais em constituições ou

\footnotetext{
${ }^{18}$ Uma das principais obrigações que os direitos sociais geram para os poderes públicos diz respeito a um dever negativo, consubstanciado no princípio da não regressividade, articulado a partir do art. $2 .^{\circ}$ do Pacto Interacional de Direitos Econômicos, Sociais e Culturais (PIDESC), que, segundo o Comitê de Direitos Econômicos, Sociais e Culturais da Organização das Nações Unidas, obriga os poderes públicos a que não adotem políticas e, em consequência, não sancionem normas que venham a piorar, sem razoável justificativa, a situação dos direitos sociais no país. Assim, "cualquier medida deliberadamente regresiva (...) requerirá la más cuidadosa consideración y deberá ser justificada plenamente por referencia a la totalidad de los derechos previstos en el Pacto y en el contexto del aprovechamiento pleno del máximo de recursos que se dispone" (COURTIS, 2006, p. 79).

${ }^{19}$ Sobre o caso alemão, v. Franco apud Courtis (2006, p. 361 et seq.).

${ }^{20}$ Em Portugal, Canotilho (2002) aponta para a existência de cláusulas constitucionais implícitas que proíbem uma "evolução reacionária" e o "retrocesso social".

${ }^{21}$ Segundo Roman (2002, p. 280), o Conselho Constitucional francês tem feito uso, ainda que de forma irregular, do chamado cliquet anti-retour.

${ }^{22} \mathrm{Na}$ Espanha, o tema da irreversibilidade dos direitos sociais foi tratado por Marín (1996, p. 91 et seq.).

${ }^{23}$ Cf. Arango apud Courtis (2006, p. 153 et seq.).

${ }^{24}$ Para Barroso $(2008 ; 2009)$ e Sarlet $(2002 ; 2005)$, trata-se de um princípio implícito, que decorre do próprio Estado democrático de direito, da dignidade humana, da segurança jurídica e da proteção à confiança (nesse sentido, v., também, Barroso e Barcellos, 2006).
} 
em tratados. Esse mínimo, o "núcleo duro" dos direitos fundamentais, relacionado ao mínimo existencial e à própria dignidade humana, será, sempre, uma barreira intransponível que obriga a uma permanente delimitação do fazer e do não fazer, da ação e da omissão, e demanda certa integração entre justiça e política, entre juízes e administradores públicos (COURTIS, 2008).

Assim, por exemplo, a Corte Constitucional da Colômbia já decidiu, em reiterados casos, que aquelas medidas que implicam retrocesso em matéria de direitos sociais devem ser consideradas medidas logicamente violadoras dos deveres do Estado e, portanto, devem estar sujeitas a um alto grau de sindicabilidade constitucional ${ }^{25}$.

Nesse sentido, sob o pretexto de vedar o retrocesso social, o Tribunal Constitucional português declarou inconstitucional uma lei que abolia o serviço nacional de saúde existente, decidindo que "Se a Constituição impõe ao Estado a realização de uma determinada tarefa (...), então, quando ela é levada a cabo, o resultado passa a ter a proteção direta da Constituição. O Estado não pode voltar atrás, não pode descumprir o que cumpriu, não pode tornar a colocar-se na situação de devedor (...). As tarefas constitucionais impostas ao Estado como garantia dos direitos fundamentais no sentido de criar certas instituições ou serviços não só o obriga apenas a criá-los, como também geram o dever de não os abolir uma vez criados" (Acórdão n. 39/84, de 11.04.1984).

No mesmo sentido, a Corte Belga de Arbitragem vem interpretando o art. 23 da Constituição belga, alusivo a direitos sociais, como se este impusesse um "efeito congelante" (standstill effect), vedando o retrocesso significativo na proteção desses direitos conferidos pelas leis no momento da adoção da Constituição. Em um caso alusivo à redução de benefícios assistenciais, a Corte belga decidiu que, no que tange ao direito à assistência social, esse efeito "congelante" veda o retrocesso significativo na proteção conferida pela legislação no momento da entrada em vigor do art. 23, preservando o direito assegurado na lei anterior mesmo diante da reforma constitucional (Caso n. ${ }^{\circ}$ 5/2004, de 14.01.2004).

$\mathrm{Na}$ África do Sul, a Corte Constitucional decidiu, no caso Government of the Republic of South Africa and Others vs. Grootboom and Others, que o Estado não havia tomado as medidas razoáveis necessárias, dentro dos recursos disponíveis, para concretizar

\footnotetext{
${ }^{25}$ A Corte colombiana já declarou inconstitucionais, assim, leis que foram consideradas regressivas em áreas como pensões (decisão T-789/2002), acesso aos serviços de saúde (decisão T-671/2002), educação (decisão C931-2004) e moradia (decisão T-1318/2005).
} 
progressivamente o direito à moradia, pois os programas habitacionais oferecidos não previam nenhuma espécie de auxílio emergencial àqueles que não possuíam acesso a um abrigo básico; ordenou ao Estado, no caso Minister of Health and Others vs. Treatment Action Campaign and Others, a implantação de um programa oficial para a prevenção da transmissão, de mãe para filho, do vírus HIV; declarou a inconstitucionalidade da exclusão dos imigrantes dos planos de benefícios da seguridade social (Mahlaule vs. Minister of Social Development, Khosa vs. Minister of Social Development); e emitiu sucessivas ordens para impedir deslocamentos urbanos e assegurar o pleno acesso de pessoas a programas de reassentamento (Port Elizabeth vs. Various Occupiers; Jaftha vs. Schoeman and Others; President of RSA and Another vs. Modderklip Boerdery (Pty) Ltd and Others; Van Rooyen vs. Stoltz and Others; Occupiers of 51 Olivia Road, Berea Township And Or. vs. City of Johannesburg and Others).

O Supremo Tribunal Federal brasileiro, por sua vez, julgou procedente a Ação Direta de Inconstitucionalidade n. ${ }^{\circ}$ 1946/DF para dar, ao art. 14 da Emenda Constitucional n. ${ }^{\circ}$ 20, interpretação conforme a Constituição, sob o pretexto de vedar o retrocesso social (a limitação - teto máximo - do valor do benefício) no direito social à licença-maternidade remunerada.

A obrigação de não regressividade em matéria de direitos sociais está relacionada, por outro lado, a uma obrigação de progressividade (PERTENCE apud COURTIS, 2006). Esse princípio autoriza os poderes públicos a adotarem programas e políticas de desenvolvimento de direitos sociais de maneira gradual, na medida em que existam recursos disponíveis (a reserva do possível), mas desautoriza aos Estados a postergação indefinida da satisfação dos direitos em pauta. Pelo contrário, demanda ações concretas, começando pela de demonstrar, de fato, que estão realizando o máximo de esforços, e até o máximo de recursos disponíveis, para a satisfação, ao menos, do conteúdo essencial dos direitos sociais e para dar soluções, de forma prioritária, aos grupos sociais em situação de maior vulnerabilidade.

Todos os direitos - e não só os direitos sociais - têm um custo (HOLMES, SUNSTEIN, 1999). Os direitos civis e políticos são, também, direitos prestacionais, de certa forma. Assim, o direito de propriedade, por exemplo, não demanda apenas, como habitualmente aponta o pensamento liberal clássico, a ausência de interferências arbitrárias, mas um elevado número de prestações públicas manifestamente onerosas, que vão da manutenção de diversos tipos de registros - de propriedade automotora, imobiliária, industrial, etc. - à manutenção de forças de segurança e de tribunais que possam garantir o cumprimento dos contratos que envolvem a 
propriedade. O direito político de voto envolve, igualmente, uma ampla e onerosa infraestrutura, que inclui desde questões mínimas, como urnas, cédulas eleitorais, etc., a outras mais complexas, como escrutinadores, mecanismos de contagem, recontagem e registros, logística, órgãos jurisdicionais, etc. Os direitos civis e políticos comportam, da mesma forma que os direitos sociais, uma dimensão distributiva, cuja satisfação demanda múltiplos recursos.

Portanto, não apenas os direitos sociais implicam custos para o Estado; os direitos civis e políticos, mesmo quando exigem uma abstenção do Estado e/ou dos particulares, ou seja, a não intervenção na esfera de autonomia e liberdade dos indivíduos, dependem de uma gravosa estrutura estatal para a sua realização. O que está em jogo, portanto, normalmente, não é como garantir direitos "caros", mas decidir como e com que prioridade serão alocados os recursos que todos os direitos - e não só os sociais - exigem para a sua satisfação.

Soma-se a isso uma tradição, em alguns casos, como o brasileiro, segundo a qual as decisões produzidas no processo deliberativo orçamentário têm sido superadas sem maior cerimônia por atos do Poder Executivo central, que simplesmente retém verbas, sem nem mesmo expor os motivos para tanto (MENDONÇA, 2008). A inexecução do orçamento, com a promoção de cortes que atingem áreas em que a atuação do Estado é notoriamente deficiente, relacionadas a direitos sociais, cria amplas distorções no âmbito da reserva do possível, com francas violações aos direitos fundamentais das pessoas (SABBAG, 2006).

Portanto, a escassez orçamentária, por si só, não pode ser vista como argumento suficientemente sólido para o afastamento do imperativo da efetivação dos direitos sociais, sobretudo do direito fundamental à saúde, relacionado ao mínimo existencial e à dignidade humana, esse núcleo mínimo absolutamente protegido, contra o qual não cabem quaisquer limitações, mesmo em tempos de crises (ALEXY, 1994): ainda que os recursos públicos sejam limitados, o Estado deve alocar verbas orçamentárias específicas para a efetivação dos direitos sociais, na medida do possível, mas sempre realizando máximo esforço na persecução das garantias dos direitos sociais.

Por isso, num contexto de disputas alocativas, onde o que está em jogo, na realidade, é decidir como e com que prioridade serão alocados os recursos que todos os direitos - e não só os direitos sociais - exigem para a sua efetivação, o poder político, ao invocar a reserva do possível, deve, sempre, demonstrar que está fazendo o máximo de força, em todos os campos 
(financeiro, pessoal, tecnológico, etc.), até o máximo possível, e que está priorizando, na sua atuação, os grupos mais vulneráveis.

De fato, a ideia da reserva do possível vem acompanhada habitualmente de três falácias, empregadas para justificar a denegação de direitos sociais fundamentais ao cidadão.

A primeira dessas falácias apoia-se no argumento de que os direitos sociais seriam direitos de segunda ordem - de segunda geração -, e, portanto, em termos teórico-dogmáticos, direitos de difícil tutela, fluídos, subordinados, na sua concretização, à concretização primeira dos direitos civis e políticos. A este argumento opõe-se o fato de que os direitos sociais não se justificam simplesmente para compensar desigualdades sociais, mas correspondem a núcleos integradores e legitimadores do bem comum, pois é através deles que se poderá garantir a segurança, a liberdade, a sustentação democrática e a continuidade da sociedade humana: são direitos fundamentais que, atuando como premissas materiais para o exercício de outros direitos, são concomitantes meio e condição para a promoção da real liberdade e da real autonomia do homem, da democracia e de outros altos objetivos do Estado democrático de direito.

A segunda falácia está relacionada com o argumento de que a exigibilidade dos direitos sociais está condicionada ao vigor econômico estatal. No entanto, o certo é que a existência de recursos públicos disponíveis para possibilitar esses direitos está associada a escolhas que definirão a destinação dos recursos por meio de políticas públicas. Dessa forma, o argumento da necessidade de uma economia forte, por si só, não é verdadeiro, bastando alguma vontade política para destinar os recursos necessários proporcionalmente, de acordo com o tamanho da economia, e racionalmente, de acordo com as prioridades da sociedade.

A terceira falácia está mais diretamente relacionada ao próprio argumento da reserva do possível. Não se pode vincular a realização dos direitos sociais à existência de recursos ignorando que os custos são inerentes à realização de todos os direitos, inclusive dos direitos civis e políticos, de forma que o estabelecimento de uma relação de continuidade entre a escassez de recursos e a afirmação dos direitos acabe resultando em uma ameaça virtual à existência de todos os direitos (BIGOLIN, 2006). Além disso, a reserva do possível não é uma espécie normativa, pois não determina um estado de coisas a ser alcançado, tampouco é um mandado de otimização. Na verdade, sequer pode ser identificada como um princípio: o que se 
pondera, na realidade, sequer é a reserva do possível, mas a escassez de recursos que esta suporia.

No entanto, existe uma diferença substancial entre inexistência de recursos e eleição de prioridades na distribuição de recursos. Se é no cumprimento da função orçamentária do Estado que as teorias dos custos dos direitos e o seu corolário da reserva do possível se apresentam de forma mais evidente, o que ocorre é que o argumento da reserva do possível pode ser refutado a partir da perspectiva de que não há recursos inexistentes, mas que a realização de certos direitos sociais não se dá em virtude de questões econômicas como o pagamento de juros e ajudas ao capital especulativo, renúncias fiscais e subsídios destinados a beneficiar a atividade de certas empresas e/ou outras escolhas realizadas a partir dos interesses das elites. Existe, pois, a necessidade de diferenciar o que não é possível fazer porque não existem meios suficientes, com a observância das normas constitucionais que determinam a alocação de recursos a áreas sensíveis, como a educação, a saúde e a seguridade social em geral, e o que não é possível fazer porque os meios disponíveis foram alocados em outras prioridades.

Em síntese, os poderes públicos não podem, de fato, ser levados a fazer o impossível. No entanto, o que é possível - ou impossível - na esfera econômica deve ser provado, e não apenas presumido. Assim, como já ressaltamos, os órgãos políticos devem sempre demonstrar que estão empregando o máximo de seus esforços, até o máximo de seus recursos, para satisfazer os direitos em questão; e mais: que estão divulgando informações suficientes e claras, e ouvindo os destinatários dos direitos em questão; que estão esforçando-se para controlar e monitorar o efetivo cumprimento das políticas e programas já existentes, além de planejar para o futuro; e que, no cerne das políticas e programas que estão sendo planejados ou executados, está a solução, a curto, médio ou longo prazo, para os problemas que afetam, sobretudo, os grupos em situação de maior vulnerabilidade, mais necessitados.

Daí que eventuais reformas estruturais do sistema de seguridade social só serão válidas se puderem ser previamente justificadas, demonstrando-se que, pelas vias da reforma, está-se, na verdade, a sustentar o sistema, sem que o simples recurso retórico à "reserva do possível" possa, de per si, justificar a adoção de medidas francamente regressivas, que quebram, no sistema de solidariedade estrutural em que se ancora o direito fundamental à seguridade social, os paradigmas da expectativa e da confiança, imprescindíveis à manutenção do pacto social instituinte. 


\section{A Título de CONCLUSÃO: A NECESSIDAdE DE MOTIVAÇÃO EXPLÍCITA ACERCA DAS REFORMAS PRIMA FACIE REGRESSIVAS.}

Em síntese, uma das principais obrigações que os direitos fundamentais sociais geram para os poderes públicos, em especial no que concerne à seguridade social, diz respeito a um dever negativo, consubstanciado no princípio da não regressividade, articulado a partir do art. 2. ${ }^{\circ}$ do Pacto Interacional de Direitos Econômicos, Sociais e Culturais ${ }^{26}$, que, segundo o Comitê de Direitos Econômicos, Sociais e Culturais da Organização das Nações Unidas ${ }^{27}$, obriga os poderes públicos a que não adotem políticas e, em consequência, não sancionem normas que venham a piorar, sem razoável justificativa, a situação dos direitos sociais no país ${ }^{28}$.

A ideia de não regressividade - esse mesmo princípio de irreversibilidade das conquistas sociais - não retira, ao Estado, a possibilidade de promover certas reformas no âmbito das suas políticas públicas sociais, prima facie regressivas, por exemplo, para (re)alocar os recursos necessários à inclusão social de determinados grupos, em situação de maior vulnerabilidade. Mas os poderes públicos deverão demonstrar, sempre, à cidadania, que as alterações que pretendem promover redundam, ao final, em maior proteção dos direitos sociais, justificando-as amplamente ${ }^{29}$.

Embora, portanto, a vedação do retrocesso não seja absoluta, este - o retrocesso - deve ser plenamente justificado. Assim, aquelas medidas que implicam retrocesso em matéria de

\footnotetext{
26 "Cada um dos Estados Partes no presente Pacto compromete-se a agir, quer com o seu próprio esforço, quer com a assistência e cooperação internacionais, especialmente nos planos econômico e técnico, no máximo dos seus recursos disponíveis, de modo a assegurar progressivamente o pleno exercício dos direitos reconhecidos no presente Pacto por todos os meios apropriados, incluindo em particular por meio de medidas legislativas".

${ }^{27}$ Segundo o Comitê, "cualquier medida deliberadamente regresiva (...) requerirá la más cuidadosa consideración y deberá ser justificada plenamente por referencia a la totalidad de los derechos previstos en el Pacto y en el contexto del aprovechamiento pleno del máximo de recursos que se dispone" (Courtis, 2006, p. 79).

${ }^{28}$ Segundo Courtis (2008, p. 510), "O princípio subjacente é o de que se o Pacto Internacional de Direitos Econômicos, Sociais e Culturais requer a progressiva realização dos direitos ali incluídos - reconhecendo o caráter necessariamente gradual de seu gozo pleno -, também proíbe que os Estados tomem medidas que piorem a sua realização. Como um critério para a comparação normativa, a vedação do retrocesso significa que qualquer medida adotada pelo Estado que suprima, restrinja ou limite o conteúdo dos direitos já garantidos pela legislação, constitui violação prima facie".

${ }^{29}$ Justificação que, expondo racionalmente os motivos determinantes da sua conduta, permite sindicá-los não só quanto à sua legalidade, ou seja, à sua adequação ao ordenamento (validade), mas também quanto à existência real desses motivos e quanto à proporcionalidade da reforma prima facie regressiva. Isso implica, além da comparação "entre a legislação, os regulamentos e as práticas previamente existentes e a recentemente aprovada, de forma a avaliar seu caráter regressivo", que o Estado justifique as suas medidas regressivas, que constituem violação prima facie, devendo provar "em escrutínio mais severo, que elas são justificadas" (Courtis, 2008, p. 510).
} 
direitos fundamentais sociais, especialmente no âmbito dos direitos da seguridade social, devem ser consideradas medidas logicamente violadoras dos deveres do Estado e, portanto, devem estar sujeitas a um alto grau de sindicabilidade constitucional - só se justificando se, de fato, comprovadamente, estiverem destinadas à efetiva viabilização da própria seguridade social, tendo-se, sobretudo, em conta, as bases de viabilização possíveis a partir da necessária conciliação possível entre princípios como o da universalidade da cobertura e do atendimento, no que diz respeito à extensão dos benefícios sociais, e o da diversidade da base de financiamento, no que diz respeito ao custeio desses mesmos benefícios, com fulcro no princípio estrutural de solidariedade.

\section{REFERÊNCIAS}

ABRAMOVICH, V.; COURTIS, C. Los derechos sociales en el debate democrático. Madrid: Bomarzo, 2006.

ALEXY, R. Teoría de los derechos fundamentales. Madrid: Centro de Estudios Constitucionales, 1994.

ANDERSSON, J. Investment or cost? The role of the metaphor of productive social policies in welfare state formation in Europe and the US: 1850-2000. World Congress in Historical Sciences. Sydney: [s.n.], 2005.

BALDASARRE, A. Los derechos sociales. Bogotá: Universidad Externado de Colombia, 2001.

BARCELLOS, A. P. A eficácia jurídica dos princípios constitucionais: o princípio da dignidade da pessoa humana. Rio de Janeiro: Renovar, 2002.

BARROSO, L. R. Interpretação e aplicação da constituição. 7.ed. São Paulo: Saraiva, 2009. Vinte anos da constituição de 1988: a reconstrução democrática do Brasil. In: 
MONTESSO, C. J.; FREITAS, M. A.; STERN, M. F. C. (Org.). Direitos sociais na constituição de 1988: uma análise crítica vinte anos depois. São Paulo: LTr, 2008.

BARROSO, L. R.; BARCELLOS, A. P. O começo da história. A nova interpretação constitucional e o papel dos princípios no direito brasileiro. In: BARROSO, L. R. (Org.). A nova interpretação constitucional: ponderação, direitos fundamentais e relações privadas. 2.ed. Rio de Janeiro: Renovar, 2006.

BIGOLIN, G. A reserva do possível como limite à eficácia dos direitos sociais. Revista de Doutrina da Quarta Região, s.n., Porto Alegre, 2006. Disponível em: $<$ http://www.revistadoutrina.trf4.gov.br/artigos/Constitucional/giovani-bigolin.htm>. Acesso em: 22 abr. 2006.

BOBBIO, N. Il futuro della democrazia. Torino: Einaudi, 1995.

BÖCKENFÖRDE, E.-W. Recht, Freiheit, Staat: Studien zur Rechtsphilosophie, Staatstheorie und Verfassungsgeschichte. Frankfurt am Main: Suhrkamp, 1991.

BODIN, J. Los seis libros de la república. Caracas: Instituto de Estudios Políticos, 1966.

BOROWSKI, M. La estructura de los derechos fundamentales. Bogotá: Universidad Externado de Colombia, 2003.

CANOTILHO, J. J. G. Direito constitucional e teoria da constituição. 5.ed. Coimbra: Almedina, 2002.

CARBONELL, M.; PARCERO; J. A. C.; VÁZQUEZ, R. (Org.). Derechos sociales y derechos de las minorías. 2.ed. México: Porruá-UNAM, 2001.

CARÍAS, A. B. Política, estado y administración pública. Caracas: Ateneo, 1979. 
COURTIS, C. (Org.). Ni un paso atrás: la prohibición de regresividad en materia de derechos sociales. Buenos Aires: CELS, 2006.

COURTIS, C. Critérios de justiciabilidade dos direitos econômicos, sociais e culturais: uma breve exploração. In: SOUZA NETO, C. P.; SARMENTO, D. (Org.). Direitos sociais: fundamentos, judicialização e direitos sociais em espécie. Rio de Janeiro: Lumen Juris, 2008. DÍAZ, E. Sociología y filosofía del derecho. Madrid: Taurus, 1971.

ESPING-ANDERSEN, G. The three worlds of welfare capitalism. Princeton: Princeton University, 1998.

FERRAJOLI, L. Derecho y razón. Teoría del garantismo penal. Madrid: Trotta, 1995.

FERRAJOLI, L. et al. Los fundamentos de los derechos fundamentales. Madrid: Trotta, 2001.

HARRINGTON, J. The commonwealth of Oceana and a system of politics. Cambridge: J. G. A. Pocock, 1992.

HART, H. The concept of law. Ofxord: Clarendon, 1961.

HOLMES, S.; SUNSTEIN, C. The cost of rights: why liberty depends on taxes. New York: Norton, 1999.

KLIKSBERG, B. O desafio da exclusão: para uma gestão social eficiente. São Paulo: FUNDAP, 1997.

LAPORTA, F. Imperio de la ley y seguridad jurídica. In: DÍAZ, E.; COLOMER, J. L. (Org.). Estado, justicia, derechos. Madrid: Alianza, 2002.

LOCKE, J. Segundo tratado sobre el gobierno civil. Madrid: Alianza, 1990. 
LUÑO, A. P. Derechos humanos, estado de derecho y constitución. 6.ed. Madrid: Tecnos, 1999.

MARÍN, A. O. Estado social y crisis económica. Madrid: Complutense, 1996.

MARSHALL, T. H. Citizenship and social class, and other essays. Cambridge: Cambridge University, 1992.

MARSHALL, T. H.; BOTTOMORE, T. Ciudadanía y clase social. Madrid: Alianza, 1998.

MARTÍNEZ, G. P.-B. Curso de derechos fundamentales: teoría general. Madrid: Universidad Carlos III, 1995.

MENDONÇA, E. Da faculdade de gastar ao dever de agir: o esvaziamento contramajoritário das políticas públicas. In: SOUZA NETO, C. P.; SARMENTO, D. (Org.). Direitos sociais: fundamentos, judicialização e direitos sociais em espécie. Rio de Janeiro: Lumen Juris, 2008.

MIRAVET, P. El ingreso ciudadano. In: ABRAMOVICH, V.; AÑON, M. J.; COURTIS, C. (Org.). Derechos sociales: instrucciones de uso. México: Fontamara, 2003.

MONTESQUIEU, C. Oeuvres complètes. Paris: Gallimard, 1951.

OLIVEIRA, M. V. Previdência social. Rio de Janeiro: Freitas Bastos, 1989.

PISARELLO, G. Los derechos sociales y sus garantías. Madrid: Trotta, 2007.

PLATÃO. Platón: obras completas. Madrid: Medina y Navarro, 1872.

POLANYI, C. La gran transformación: crítica del liberalismo económico. Madrid: La Piqueta, 1998. 
RAWLS, J. A theory of justice. Oxford: Oxford University, 1980.

REIS, J. R. A vinculação dos particulares aos direitos fundamentais nas relações interprivadas: breves considerações. In: LEAL, R. G; REIS, J. R. (Org.). Direitos sociais e políticas públicas: desafios contemporâneos. Santa Cruz do Sul: Edunisc, 2005.

ROMAN, D. Le droit public face à la pauvreté. Paris: LGDJ, 2002.

ROUSSEAU, J.-J. Le contrat social. Paris: Armand Colin, 1962.

SABBAG, C. Orçamento e desenvolvimento - recurso público e dignidade humana: o desafio das políticas públicas desenvolvimentistas. São Paulo: Millennium, 2006.

SARLET, I. W. Dignidade da pessoa humana e direitos fundamentais na constituição federal de 1988. Porto Alegre: Livraria do Advogado, 2002.

A eficácia dos direitos fundamentais. 5.ed. Porto Alegre: Livraria do Advogado, 2005.

SIMÕES, A. Princípios de segurança social: previdência social e assistência social. São Paulo: [s.e.], 1967.

THOME, C. F. O princípio da igualdade em gênero e a participação das mulheres nas organizações sindicais de trabalhadores. Tese de Doutorado (Direito). São Paulo. Universidade de São Paulo. 2012.

WEBER, M. Economía y sociedad. México: Fondo de Cultura Económica, 1964.

YAMASHITA, D. Princípio da solidariedade em direito tributário. In: GRECO, Marco Aurélio;

GODOI, Marciano Seabra de (Coord.). Solidariedade social e tributação. São Paulo: Dialética, 2005 . 